\title{
BCI-based games and ADHD
}

\author{
Jogos baseados na BCI e TDAH \\ Juegos basados en BCI y TDAH
}

Received: 03/16/2021 | Reviewed: 03/22/2021 | Accept: 04/12/2021 | Published: 04/21/2021

Vasiliki Bravou

ORCID: https://orcid.org/0000-0003-3922-7950

N.C.S.R. "Demokritos", Greece

E-mail: vbravou@iit.demokritos.gr

Athanasios Drigas

ORCID: https://orcid.org/0000-0001-5637-9601

N.C.S.R. "Demokritos", Greece

E-mail: dr@iit.demokritos.gr

\begin{abstract}
Attention Deficit Hyperactivity Disorder (ADHD) is a neurological condition characterized by cognitive task difficulty, impulsivity, hyperactivity and loss of attention. It can persist into adulthood with negative academic and socioprofessional outcomes. Neurofeedback treatments have been shown as effective for training the attention ability in children with ADHD. It has been found that interactive multi-player games are ideal from a therapeutic and long-term usage point of view due to their higher social motivation and cooperation among children with ADHD. In this study we conducted a semi-systematic review, with the goal of gathering findings from empirical and theoretical works in order to deepen our understanding about the use of Brain Computer Interface (BCI)-based for children and adults with ADHD, as a method to ameliorate the symptoms of their disorder.
\end{abstract}

Keywords: Brain-computer interface; BCI; Attention deficit hyperactivity disorder; ADHD; Serious games.

\section{Resumo}

O Transtorno do Déficit de Atenção com Hiperatividade (TDAH) é uma condição neurológica caracterizada por dificuldade de tarefa cognitiva, impulsividade, hiperatividade e perda de atenção. Pode persistir na idade adulta com resultados acadêmicos e socioprofissionais negativos. Os tratamentos de neurofeedback têm se mostrado eficazes para treinar a habilidade de atenção em crianças com TDAH. Foi descoberto que os jogos interativos para vários jogadores são ideais do ponto de vista terapêutico e de uso de longo prazo devido à sua maior motivação social e cooperação entre crianças com TDAH. Neste estudo realizamos uma revisão semissistemática, com o objetivo de reunir achados de trabalhos empíricos e teóricos a fim de aprofundar nossa compreensão sobre o uso de jogos baseados em Brain Computer Interface (BCI) para crianças e adultos com TDAH, como um método para melhorar os sintomas de seu transtorno.

Palavras-chave: Brain-computer interface; BCI; Transtorno do déficit de atenção com hiperatividade; TDAH; Jogos sérios.

\section{Resumen}

El Trastorno por Déficit de Atención e Hiperactividad (TDAH) es una afección neurológica caracterizada por dificultad cognitiva en la tarea, impulsividad, hiperactividad y pérdida de atención. Puede persistir hasta la edad adulta con resultados académicos y socioprofesionales negativos. Se ha demostrado que los tratamientos de neurofeedback son eficaces para entrenar la capacidad de atención en niños con TDAH. Se ha descubierto que los juegos interactivos para múltiples jugadores son ideales desde un punto de vista terapéutico y de uso a largo plazo debido a su mayor motivación social y cooperación entre los niños con TDAH En este estudio realizamos una revisión semi-sistemática, con el objetivo de recopilar hallazgos de trabajos empíricos y teóricos con el fin de profundizar nuestra comprensión sobre el uso de juegos basados en Brain Computer Interface (BCI) para niños y adultos con TDAH, como método para mejorar los síntomas de su trastorno.

Palabras clave: Brain-computer interface; BCI; Trastorno por déficit de atención e hiperactividad; TDAH; Juegos serios.

\section{Introduction}

Attention Deficit Hyperactivity Disorder (ADHD) is a neurological condition characterized by cognitive task difficulty, impulsivity, hyperactivity and loss of attention (Zafar et al., 2017). It is a developmental, neuropsychiatric disorder of childhood which can persist into adulthood with negative academic and socio-professional outcomes (Lim et al., 2019). Children with 
inattention symptoms usually show passive, lethargic attention problems or a deficit of sustained attention, such as procrastination, hesitance, and forgetfulness (Qian et al., 2018). Neurofeedback treatments have been shown as effective for training the attention ability in children with ADHD (Blandon et al., 2016). Neurofeedback is a form of Brain-Computer Interface (BCI) where the user is receiving feedback based on the frequency components in the electroencephalogram (EEG). BCI is an interface between the brain and an external appliance which allows signals from the brain to control the external device (Rohani \& Puthusserypady, 2015). A BCI-based attention training program doesn't include medication, is much safer than other pharmacological methods, is easy to learn and it can be implemented at home (Qian et al., 2018). It has been found that interactive multiplayer games are ideal from a therapeutic and long-term usage point of view due to their higher social motivation and cooperation among children with ADHD; although there are some disadvantages including unreliability of electroencephalography (EEG) feedback and the risk of distracting the player from the collaborative environment (Arrambide, K. et al., 2019). In this study we are going to explore the use of several BCI-based games for children and adults with ADHD as a method to ameliorate the symptoms of their disorder.

\section{Methodology}

In this study we conducted a semi-systematic review, with the goal of gathering findings from empirical and theoretical works in order to deepen our understanding about the use of BCI-based games for children and adults with ADHD, as a method to ameliorate their symptoms. The semi-systematic or narrative review approach is intended for subjects that have been conceived and researched in different ways by different groups of researchers from various disciplines (Snyder, 2019).

According to the steps of this review type, an search for scientific articles was carried out in Google Scholar, PubMed $\kappa \alpha_{1}$ Scopus databases, with the time frame from 2010 to 2020. The research was carried out using the descriptors Brain-Computer Interface, BCI, Attention Deficit Hyperactivity Disorder, ADHD and Serious Games. For the selection of articles, the Boolean operator "AND" was also used, in order to restrict the search to articles that presented each term simultaneously.

Of the retrieved articles, fourteen (14) were included in this review and were separated according to the whether the BCI-game analysed in each article referred to children with ADHD or to adults with ADHD.

\section{BCI-based Games}

\subsection{BCI-based Games for Children}

Lim et al. (2010), investigated if by the use of Brain-Computer Interface (BCI) based games the inattentive symptoms of children with Attention Deficit Hyperactivity Disorder could be improved. The game aims to meliorate the attention and concentration levels of the subjects. The subjects didn't have to go through evaluation before the intervention because the BCI device used can adjust on its own to the user's upper limit of attention on a given task. After 10 weeks and 20 sessions of therapy, results indicate an improvement over the ADHD symptoms. The intervention and control groups showed amelioration in their incentive and hyperactive symptoms but the sample size of the subjects was small and could have influenced the statistical power of the study (Lim et al., 2010).

Lim et al. (2012), presented a Brain-Computer Interface based game, named CogoLand, which aims to train the attention ability of children with combined and inattentive subtypes of Attention Deficit Hyperactivity Disorder (ADHD). The game could be adjusted according to the child's performance. A BCI device, that uses dry electroencephalogram (EEG) electrodes and is connected to the computer via Blue-tooth, is used in order to observe the attention levels of the subjects and control an avatar with the signals produced by the device. After 8 weeks and 24 sessions of therapy the outcomes showed significant improvement of the inattentive symptoms of children with ADHD. Parents of children with the combined subtype of ADHD, have also reported 
a significant improvement in their hyperactive-impulsive symptoms on the ADHD Rating Scale. When these children subsequently received monthly training sessions, the behavioural improvements were sustained but did not improve further. Those with more serious symptoms were also those that showed greater development (Lim et al., 2012).

Lim et al. (2019), investigated the use of a brain-computer interface as a tool for improving the inattentive symptoms of children with ADHD. The program consisted of a training game which, with the use of EEG reading head-band, allowed children to accelerate the game's character by increasing the level of their concentration. At least 3 sessions for 8 weeks of the BCI-based attention training program are needed in order to maintain the amelioration of the participants' ADHD indications. This is a healthy, engaging and well tolerated intervention. It can theoretically be used as an adjunctive treatment or for treating milder ADHD symptoms. Future experiments would be able to examine the impact of various training intensities. It is possible to expand this strategy into a home-based treatment alternative and to provide greater convenience and accessibility (Lim et al., 2019).

Blandón et al. (2016), presented a study about measuring and potentially ameliorating the attention of children with ADHD by the use of a videogame, named Har-vest Challenge. The game uses a BCI device to measure the attention levels of the subjects and use them as inputs for the game. Also, a Matlab software toolbox, named NeuroRead, was created in order to process the BCI signals. The attention of the subjects seems to be augmenting since their game progress kept improving. Videogames can be a motivational tool for helping children with ADHD to solve attention issues, offering highly immersive activities that seek to establish good levels of treatment adherence. The study showed how physiological signals could not only be used to generate challenging video games by adding wearable BCI sensors, but also to generate useful medical information to better understand the complicated phenomenon of ADHD (Blandon et al., 2016).

Arrambide et al. (2019), designed the Brain-Computer Interface game, named "Orbit", in order to investigate if children with ADHD would be more intent to treatment with neurofeedback. The player affects the game by concentrating and focusing, elements that can train the child's attention. However, the game has a single player and is not promoting social motivation through collaboration with other players. The use of collaborative multiplayer games within the therapy for children with ADHD has been shown to be appropriate for long-term use. The study showed that a mixture of social help from an non-playable character (NPC) should also be generated at the start of the therapy and playing with another child in the further course of the therapy (Arrambide, K. et al., 2019).

In 2019, Park et al., analysed the development of a game for ameliorating the reading capacity of children with Attention Deficit Hyperactivity Disorder (ADHD). Children with ADHD have problems reading as they can omit words or phrases, lose their position in the text, read very slowly or very quickly, fail to order events in a story, find it difficult to recognise the main concept of a passage and forget what they are reading. The game comprises a story like fairy tale, it uses a Brain-Computer Interface (BCI) as a tool for measuring the attention and focus of the children and a motion sensing device, in order for the user to be able to control the game. In providing an alternative treatment scheme for children with ADHD, this study plays an important role by enabling them to support or empathize with others by tracking their own behaviour. The game's immediate intervention input allows children to control their actions themselves. This study is worthwhile because the qualitative research found positive improvements in the everyday lives of children (Park et al., 2019).

In 2015, Rohani and Puthusserypady, examined if by the use of the P300 potential, a brain signal measured by a BrainComputer (BCI) device, the attention of people with Attention Deficit Hyperactivity Disorder (ADHD) can be enhanced. Attention games running inside a 3D Virtual Reality (VR) classroom were designed, in order to observe the attention level of the subjects. An accessible, compact immersive experience is suggested, with added visual and auditory distractions with cheap hardware and a simple "off-axis perspective projection" algorithm that can easily be used directly in classrooms, institutions or private homes. This study indicates that there are going to be positive results if the VR classroom is used in people with ADHD 
(Rohani \& Puthusserypady, 2015).

Muñoz et al. (2015), presented a study about the planning and deployment of a videogame, named "The Harvest Challenge", that uses a Brain-Computer Interface (BCI) in order to measure the neurophysiological signals of children with Attention Deficit Hyperactivity Disorder (ADHD). Through the basic mental phases, relaxation and concentration, the videogame's dynamic creates an interaction mode. The brain signal is captured by a portable BCI sensor when a child reaches a particular focus level, which sends the signals wirelessly to the video game to ensure the interactions are programmed. The aims of the game are to improve the writing, planning, following instructions and achieving objectives abilities of children with ADHD. The video-game was developed for use in public or private educational facilities, neuropsychological treatment centres, and could be played at home by a child who uses the smartphone version (Munoz et al., 2015).

Qian et al. (2018), presented a study about a Brain-Computer Interface (BCI)-based game, named CogoLand, which aims to unveil the neural mechanism subjacent behavioural improvement and to train the attention ability of children with Attention Deficit Hyperactivity Disorder (ADHD). The BCI game uses a headband with mounted dry electroencephalography (EEG) sensors. Each player in the game con-trolled an avatar to complete a task. If participants were more attentive, the avatar ran more quickly. The results, after 8 weeks of BCI-based treatment, show that this intervention method can help with behavioural improvement and expedite brain maturation in ADHD children, as the inattention scores in the ADHD Rating Scale drop significantly. Findings, also, illustrate the importance of network-sensitive neuroimaging approaches for discovering pathways for brain plasticity linked to intervention effectiveness in neurodevelopmental disorders such as ADHD (Qian et al., 2018).

In 2015, Craven and Groom, investigated the use of Brain-Computer Interface (BCI) games in training the task focus, education/training/health/awareness focus and medical/clinical focus ability of people with Attention Deficit Hyperactivity Disorder (ADHD). The games, which are used for the measurement of the user's attention level, are "SnappyApp", "Awkward Owls" and "Wormy Fruit". They are based on Go/No-go or Stop signals, in order for the user to appropriately response to each stimulus of the game. It is observed that there was no game ontology relevant to game description or design which includes cognitive or executive functions. This finding can be generalized from ADHD to games' mental health applications in general, and may also add physical capability aspects. This study aims to have contributed to rectify this situation (Craven \& Groom, 2016).

In 2019, Gabele et al., introduced an Augmented Reality (AR)-based multiplayer game, which utilizes a Brain Computer interface (BCI) device and haptic feedback, in order to treat children with Attention Deficit Hyperactivity Disorder (ADHD). The Mindwave headsets were used as BCI devices, in order to measure the focus level of the players. The idea presented offers an approach to complement the existing ADHD training for children, and not as a replacement for the current training. Singleplayer on-the-monitor training as well as established games by setup have their bene-fits, such as low outside distraction and possibilities for separate in-home use training with lower technological needs. As a result of the study, the strategy discussed may be performed with the therapist inside during the session or as free play at the end (Gabele et al., 2019).

\subsection{BCI-based Games for Adults}

In 2015, Ali and Puthusserypady, presented a study about a Brain-Computer Interface (BCI) system that uses steady state visually evoked potentials, which aims to improve the attention levels of people with Attention Deficit Hyperactivity Disorder (ADHD). The system has the form of a game and is comprised of a 3D classroom environment which includes 2D games on its blackboard. The game's purpose is to measure the subjects' attention levels as the environment changes. Results show that as the game environment changes from 2D to 3D and distractions are added the subjects get distracted and their attention levels drop. The findings have shown that while the levels are advancing, the accuracy decreases and time increases. 
The purpose of the BCI system is validated by these results. The higher the level, the more difficult it becomes to hold the concentration. By becoming accustomed to the BCI system, the subjects train their attention so the same results are obtained when they play the first or last stage (A. Ali \& Puthusserypady, 2015).

Alchalabi et al. (2018), introduced an Electroencephalogram (EEG)-controlled serious game, named FOCUS, the purpose of which is to detect the attention and focus of people with Attention Deficit Hyperactivity Disorder (ADHD). The game utilises the EEG Brain-Computer Interface (BCI) device EMOTIV, in order for the player to control the moves of an avatar by concentrating and using intellectual commands. The novelty of this work is not only being the first work that laid the foundations for the development of a serious EEG-controlled game for the identification of patients with ADHD, but also the results of the classification obtained were encouraging, demonstrating a clear feasibility of a robust classification method. This attention detection method proved to be very accurate in both healthy and ADHD individuals (Alchalabi et al., 2018).

In 2017, Alchalabi et al., analysed the implementation of an electroencephalogram (EEG)-controlled serious game, named "FOCUS", that aims to train and amplify the attention levels of people with Attention Deficit Hyperactivity Disorder (ADHD). The user is called to move an avatar by using only mental commands and attention abilities. The EMOTIV EPOC+ kit is used as a Brain-Computer Interface device that reads the commands. In this study two different models to classify the EEG signals according to the subjects' attention states are used: keyboard controlled and EMOTIV controlled. The results of the classification of the measured EEG data at the correct attention status are accurate and promising for further investigation in the field (Alchalabi et al., 2017).

\section{Conclusion}

Attention Deficit Hyperactivity Disorder or ADHD is one of the most diagnosed conditions in children between 8-12 years old and can persist into adulthood with negative academic and socio-professional outcomes. The main indicators of ADHD include persistent inattention, hyperactivity and impulsivity. Characteristics of this disorder may have a social and academic impact on children by influencing their everyday activities. Current established treatment methods for ADHD include medication, psychosocial or behavioural treatment, or both. Neurofeedback therapy that is based on a brain-computer interface (BCI) is a promising approach for treating people with ADHD, by normalizing their abnormal electroencephalogram (EEG) patterns. Trials demonstrate that this method is not inferior to medication and its efficacy is increased in combination with pharmacological methods.

Some suggestions for future research on the field would include larger follow-up clinical trials and well-crafted randomized controlled trials, in order to investigate more about BCI-games' effectiveness in ameliorating ADHD's inattentive symptoms. Also, male to female ratio in future trials needs to be more balanced.

\section{References}

Alchalabi, A. E., Elsharnouby, M., Shirmohammadi, S., \& Eddin, A. N. (2017, May). Feasibility of detecting ADHD patients' attention levels by classifying their EEG signals. In 2017 IEEE International Symposium on Medical Measurements and Applications (MeMeA) (pp. 314-319). IEEE.

Alchalabi, A. E., Shirmohammadi, S., Eddin, A. N., \& Elsharnouby, M. (2018). FOCUS: Detecting ADHD patients by an EEG-based serious game. IEEE Transactions on Instrumentation and Measurement, 67(7), 1512-1520.

Ali, A., \& Puthusserypady, S. (2015, August). A 3D learning playground for potential attention training in ADHD: A brain computer interface approach. In 2015 37th Annual International Conference of the IEEE Engineering in Medicine and Biology Society (EMBC) (pp. 67-70). IEEE.

Ali, Y., Mahmud, N. A., \& Samaneh, R. (2015). Current advances in neurofeedback techniques for the treatment of ADHD. Biomed. Pharma. J, 8, 65-177.

Arrambide, K., Freiman Cormier, L., Wehbe, R. R., Nacke, L. E., Gabele, M., Wagner, S., \& Hansen, C. (2019, October). The Development of" Orbit" The Collaborative BCI Game for Children with AD (H) D. In Extended Abstracts of the Annual Symposium on Computer-Human Interaction in Play Companion Extended Abstracts (pp. 341-348). 
Blandón, D. Z., Muñoz, J. E., Lopez, D. S., \& Gallo, O. H. (2016, September). Influence of a BCI neurofeedback videogame in children with ADHD. Quantifying the brain activity through an EEG signal processing dedicated toolbox. In 2016 IEEE 11th Colombian Computing Conference (CCC) (pp. 1-8). IEEE.

Borhani, S., Abiri, R., Jiang, Y., Berger, T., \& Zhao, X. (2019). Brain connectivity evaluation during selective attention using EEG-based brain-computer interface. Brain-Computer Interfaces, 6(1-2), 25-35.

Carelli, L., Solca, F., Faini, A., Meriggi, P., Sangalli, D., Cipresso, P., Riva, G., Ticozzi, N., Ciammola, A., Silani, V., \& Poletti, B. (2017). Brain-computer interface for clinical purposes: cognitive assessment and rehabilitation. BioMed research international, 2017.

Craven, M. P., \& Groom, M. J. (2015, October). Computer games for user engagement in Attention Deficit Hyperactivity Disorder (ADHD) monitoring and therapy. In 2015 International Conference on Interactive Technologies and Games (pp. 34-40). IEEE.

Enriquez-Geppert, S., Smit, D., Pimenta, M. G., \& Arns, M. (2019). Neurofeedback as a treatment intervention in ADHD: Current evidence and practice. Current psychiatry reports, 21(6), 1-7.

Fahimi, F., Guan, C., Goh, W. B., Ang, K. K., Lim, C. G., \& Lee, T. S. (2017, July). Personalized features for attention detection in children with Attention Deficit Hyperactivity Disorder. In 2017 39th Annual International Conference of the IEEE Engineering in Medicine and Biology Society (EMBC) (pp. 414-417). IEEE.

Fedotchev, A. I., Parin, S. B., Polevaya, S. A., \& Velikova, S. D. (2017). Brain-computer interface and neurofeedback technologies: current state, problems and clinical prospects. Современные технологии в медицине, $9(1)$

Fouillen, M., Maby, E., Le Carrer, L., Herbillon, V., \& Mattout, J. (2017). Erp-based BCI Training for children with ADHD: Motivations and Trial Design. In $G B C I C$.

Gabele, M., Schröer, S., Hußlein, S., \& Hansen, C. (2019). An AR Sandbox as a Collaborative Multiplayer Rehabilitation Tool for Children with ADHD. Mensch und Computer 2019-Workshopband.

Katona, J., \& Kovari, A. (2018). The evaluation of bci and pebl-based attention tests. Acta Polytechnica Hungarica, 15(3), $225-249$.

Kerous, B., Skola, F., \& Liarokapis, F. (2018). EEG-based BCI and video games: a progress report. Virtual Reality, 22(2), 119-135.

Lim, C. G., Lee, T. S., Guan, C., Fung, D. S., Cheung, Y. B., Teng, S., \& Krishnan, K. R. (2010). Effectiveness of a brain-computer interface based programme for the treatment of ADHD: a pilot study. Psychopharmacol Bull, 43(1), 73-82.

Lim, C. G., Lee, T. S., Guan, C., Fung, D. S. S., Zhao, Y., Teng, S. S. W., \& Krishnan, K. R. R. (2012). A brain-computer interface based attention training program for treating attention deficit hyperactivity disorder. PloS one, 7(10), e46692.

Lim, C. G., Poh, X. W. W., Fung, S. S. D., Guan, C., Bautista, D., Cheung, Y. B., \& Lee, T. S. (2019). A randomized controlled trial of a brain-computer interface based attention training program for ADHD. PloS one, 14(5), e0216225.

McFarland, D. J., Daly, J., Boulay, C., \& Parvaz, M. A. (2017). Therapeutic applications of BCI technologies. Brain-Computer Interfaces, 4(1-2), 37-52.

Mercado, J., Espinosa-Curiel, I., Escobedo, L., \& Tentori, M. (2019). Developing and evaluating a BCI video game for neurofeedback training: the case of autism. Multimedia Tools and Applications, 78(10), 13675-13712.

Moyosola, S. M., Alexandru, M. D., Nicole, G., Al Gayar Sarmad Monadel, S., Pavaloiu, B., \& Boiangiu, C. (2019, April). Development of a Low-Cost and User-Friendly Neurofeedback Tool to treat Depression, Insomnia, Anxiety, Pain and ADHD using an Arduino and Android Application. In 2019 International Conference on Automation, Computational and Technology Management (ICACTM) (pp. 493-499). IEEE.

Muñoz, J. E., Lopez, D. S., Lopez, J. F., \& Lopez, A. (2015). Design and creation of a BCI videogame to train sustained attention in children with ADHD. In 2015 10th Computing Colombian Conference (10CCC) (pp. 194-199). IEEE.

Park, K., Kihl, T., Park, S., Kim, M. J., \& Chang, J. (2019). Fairy tale directed game-based training system for children with ADHD using BCI and motion sensing technologies. Behaviour \& Information Technology, 38(6), 564-577.

Qian, X., Loo, B. R. Y., Castellanos, F. X., Liu, S., Koh, H. L., Poh, X. W. W., Krishnan, R., Fung, D., Chee, M. W., Guan, C., Lee, T. S., Lim, C. G., \& Zhou, J. (2018). Brain-computer-interface-based intervention re-normalizes brain functional network topology in children with attention deficit/hyperactivity disorder. Translational psychiatry, 8(1), 1-11.

Rohani, D. A., \& Puthusserypady, S. (2015). BCI inside a virtual reality classroom: a potential training tool for attention. EPJ Nonlinear Biomedical Physics, 3 , $1-14$.

Snyder, H. (2019). Literature review as a research methodology: An overview and guidelines. Journal of Business Research, 104, 333-339.

Zafar, M. B., Shah, K. A., \& Malik, H. A. (2017, April). Prospects of sustainable ADHD treatment through Brain-Computer Interface systems. In 2017 International Conference on Innovations in Electrical Engineering and Computational Technologies (ICIEECT) (pp. 1-6). IEEE.

Zuberer, A., Brandeis, D., \& Drechsler, R. (2015). Are treatment effects of neurofeedback training in children with ADHD related to the successful regulation of brain activity? A review on the learning of regulation of brain activity and a contribution to the discussion on specificity. Frontiers in human neuroscience, 9 , 135. 